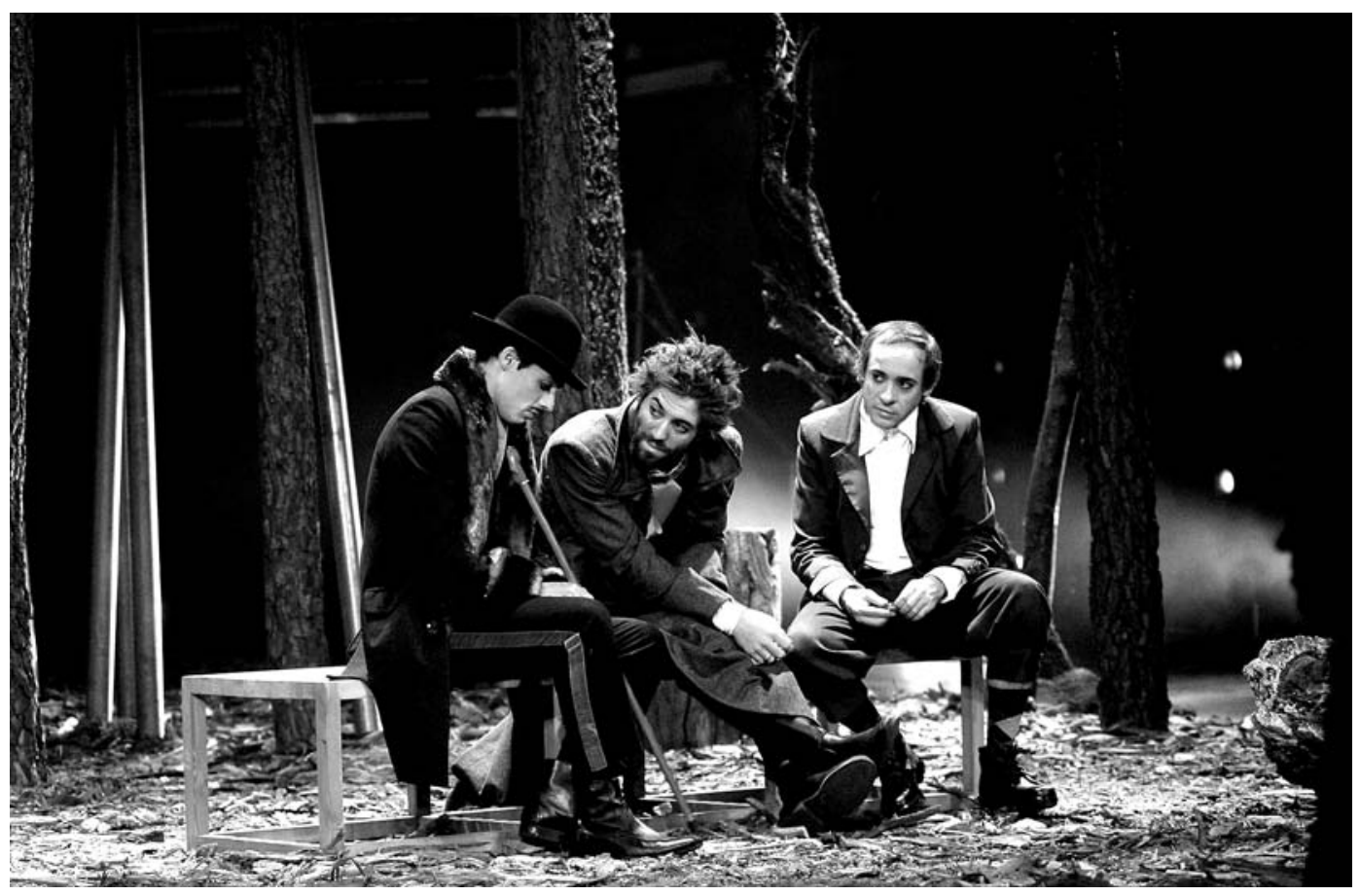

\title{
Mentira e método
}

\author{
Paulo Filipe Monteiro
}

Titulo: Quando o Inverno chegar. Texto: José Luis Peixoto. Dramaturgia: Marco Martins, Nuno Lopes, Beatriz Batarda, Dinarte Branco, Gonçalo Waddington. Encenação: Marco Martins. Cenografia: João Mendes Ribeiro. Figurinos: Adriana Molder. Música original e direção musical: Pedro Moreira. Desenho de Luz: Nuno Meira. Voz e elocução: Luis Madureira. Caracterização: Sano de Perpesac. Adereços: Carlos Matos. Interpretação: Beatriz Batarda, Dinarte Branco, Gonçalo Waddington, Nuno Lopes. Músicos:Carla Simões, Paulo Pacheco, Pedro Moreira, Otto Pereira/Liviu Scripcaru, Luis Gomes/Ana Rita Pratas, Andreia Marques/Ana Isabel Dias. Produção: São Luiz Teatro Municipal. Local e data de estreia:Teatro São Luiz, 7 de Junho de 2007.

A singularidade deste espectáculo começa pela singularidade das suas condições de produção. Um grupo de actores (Gonçalo Waddington, Nuno Lopes e Beatriz Batarda) e o realizador de cinema Marco Martins (que se notabilizara pelo filme Alice, com estes actores) propuseram-se ao director do teatro São Luiz fazer um espectáculo. E Jorge Salavisa respondeu com a proposta de trabalharem com José Luís Peixoto, um escritor da mesma geração (nascida nos anos 70), que já no São Luiz assinara a sua primeira peça (que resultou no notável À manhã do Teatro Meridional). Tal contra-proposta resultava, nas palavras do próprio Salavisa, do "desejo de dar continuidade ao trabalho como dramaturgo deste

Salvo indicação em

contrário, todas as citações são do programa do espectáculo. jovem e talentoso escritor. Porque às vezes em Portugal a escrita teatral peca por ser demasiado avulsa e porque não há, de facto, muitas condições para o desenvolvimento sustentado de uma dramaturgia nossa, original" ${ }^{11}$.

A este singular ponto de partida podia ainda assim ter-se seguido a metodologia tradicional do teatro - ou do cinema. Mas isso não aconteceu. Inspirando-se vagamente na Montanha mágica de Thomas Mann, Peixoto propôs a situação de três homens fechados num sanatório há vários anos, que num passeio pela floresta encontram uma rapariga grávida à beira do suicídio (inicialmente inspirada na Helena de Luz em Agosto de Faulkner); e propôs também algumas cenas, "como forma de apontar horizontes especificos para as vozes das personagens". Seguiram-se vários meses (de Novembro de 2006 a Maio de 2007) de trabalho sobre essas propostas. Um processo de escrita colectiva que costuma ser raro no teatro ou no cinema. Mas há bons exemplos, como o do dramaturgo e cineasta Mike Leigh (aliás referido por Marco Martins): mesmo nos seus filmes, apesar dos habituais e apertados constrangimentos de produção, Leigh consegue fazer vingar um método próprio, em que o guião não está todo escrito e as filmagens podem parar durante semanas para incorporar as sugestões e exigências dos actores, os quais, ao encarnarem as personagens, são afinal quem melhor as conhece na pele. Foi assim que, a partir da proposta de Peixoto, cada actor (os três iniciais mais Dinarte Branco) "iniciou uma exploração da sua personagem, criando-lhe a sua dimensão psicológica e física, atribuindo-Ihe um passado, um presente e uma expectativa de futuro, conferindo-Ihe gostos, ambições e recalcamentos" ${ }^{2}$.

A partir da criação destas personagens desenvolveramse as habituais discussões de mesa mas também as improvisações - menos habituais, sobretudo quando, como neste caso, foram sistemáticas, intensas e demoradas. São alguns os encenadores portugueses que recorrem a improvisações mesmo diante duma peça previamente escrita: porque o sentido de um texto não deve ser predeterminado por um debate exclusivamente feito à 


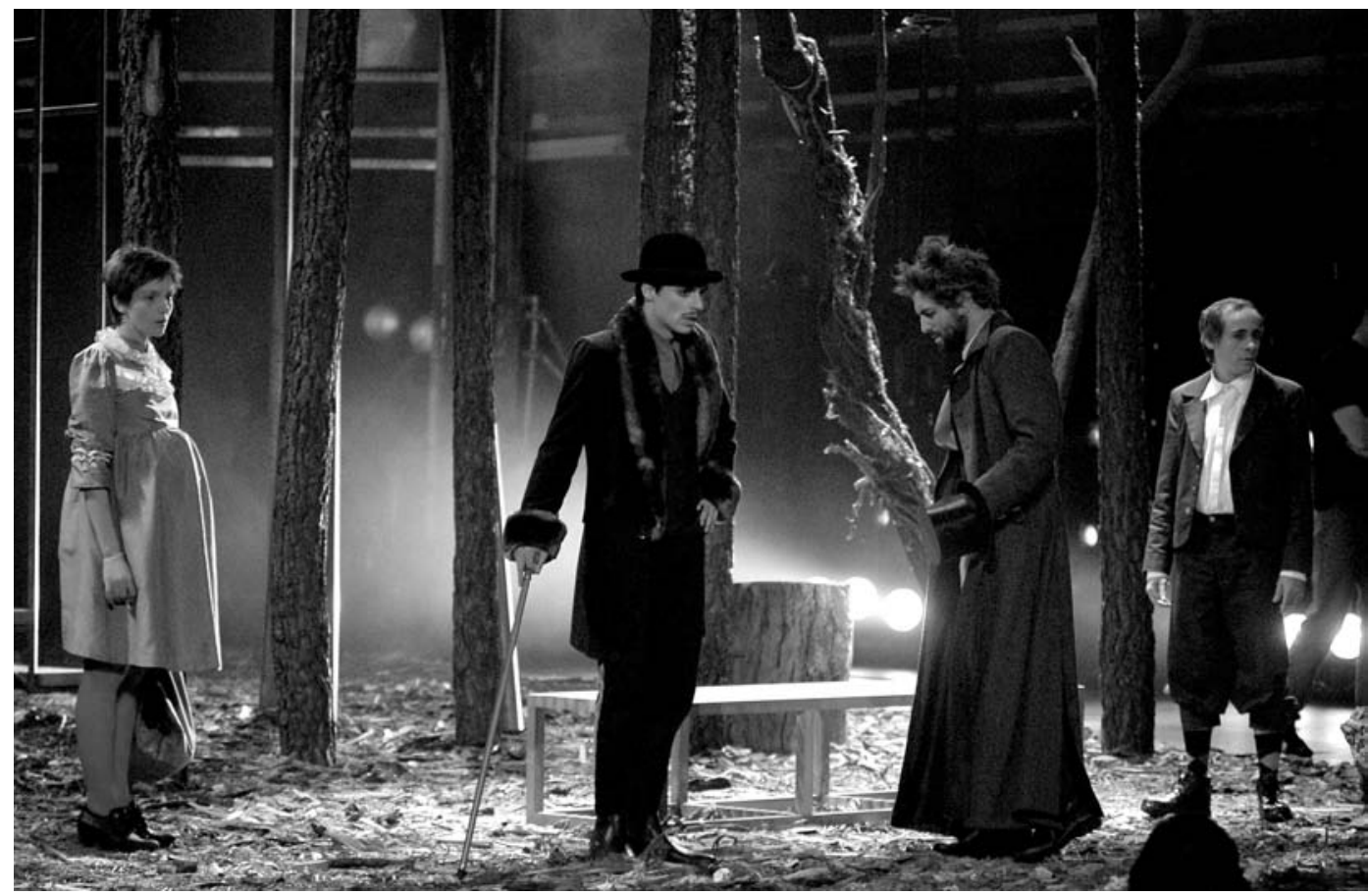

Quando o Inverno chegar,

de José Luis Peixoto,

enc. Marco Martins,

Teatro São Luiz, 2007

(Beatriz Batarda,

Gonçalo Waddington,

Nuno Lopes,

Dinarte Branco),

fot. José Frade.

mesa. Mas aqui tratou-se de encontrar não apenas o subtexto como o próprio texto da peça. Depois Marco Martins filmou e montou o que tinha sido colectivamente criado. E em seguida José Luís Peixoto rescreveu: "em alguns casos", diz, "o resultado final reflecte um trabalho feito a partir dessas ideias [sugeridas pelos próprios actores]; noutros casos, trata-se, praticamente, da transcrição, e necessário aperfeiçoamento, dessas mesmas ideias." Dai que na ficha do espectáculo surja: "texto de José Luis Peixoto" e "dramaturgia" do encenador e dos quatro actores. Honra Ihes seja feita.

Quase tudo neste espectáculo recomenda que tal método venha a ser adoptado mais vezes. Ergueu-se assim um magnífico texto de teatro, capaz de dialogar com alguns clássicos da dramaturgia. 0 quase referese apenas ao facto de algumas improvisações da primeira parte não terem sido sacrificadas à economia narrativa e dramática. Compreende-se: a riqueza e frescura do jogo dos actores era surpreendente e fascinante; tanto mais surpreendente quanto infelizmente estamos pouco habituados a uma presença em palco que parece fazer nascer em cada noite, diante dos olhos do público, as personagens como seres vivos, cheios de nuances, sentindo-se na hora performativa um jogo cúmplice e não totalmente predefinido entre elas; tanto mais notável quanto essa cumplicidade nunca anulava os claros contrastes que as definiam e as lutas de poder entre elas. Mas a segunda parte do espectáculo fazia sentir uma certa duração excessiva: por culpa de alguma escusada deriva na primeira parte, já que só no fim dela a estrutura dramática ganhava densidade.

Marco Martins soube, nesta sua primeira encenação para teatro, encontrar um registo ao mesmo tempo inovador e bem definido. Tal como no espectáculo The Pillowman, encenado em 2006 no Teatro Maria Matos por outro cineasta, Tiago Guedes (também com quatro actores, um dos quais Gonçalo Waddington), tem-se a impressão de que o teatro está a ser enriquecido por gente que, não estando formatada no cânone teatral, tem a coragem de construir universos próprios, suigeneris, e a capacidade de os transmitir com clareza. Em Quando o Inverno chegar sentem-se algumas referências, claro: além de Thomas Mann e Faulkner, escreve o próprio encenador, "será impossivel não pensar em Beckett e Tchekov": e poderiamos acrescentar Kafka, porque é para esse lado que o absurdo por vezes se inclina. Mas tais referências surgem unificadas e ultrapassadas por uma ideia forte, que o encenador remete para as leis de Newton, sobretudo a da inércia: um corpo que esteja em movimento ou em repouso tende a manter o seu estado inicial; ou seja, traduz Marcos Martins, "todos os corpos são 'preguiçosos'": o espectáculo "propõe-nos um universo ficcional abstracto, com regras e tempos próprios, dominado pela inércia, escondida atrás da máscara de uma doença (...), pela perversidade quase infantil das personagens que, incapazes de se porem em causa, presas às memórias angustiantes de um passado distante e temerosas do seu futuro, optam por ficar paradas." Nessa espécie de suspensão no tempo e no espaço sentem-se as afinidades electivas com Beckett e Tchekov. Mas existem afinal reviravoltas na narrativa que contrariam tal inércia.

Às referências literárias e científicas, o encenador soube juntar referências visuais: "as imagens levantam inúmeras questões e possuem histórias escondidas para além daquela que vemos, estimulam o pensamento e a imaginação. Por isso, confrontei os actores com imagens de Anthony Goicolea e todo o seu trabalho, em fotografia e desenho, sobre a perversidade juvenil de rapazes fechados em espaços de clausura, bem como o de artistas como Bernard Faucon, Loretta Lux ou Paula Rego". Soube também implementar e incentivar a metodologia de improvisações. Nelas ou a partir delas soube dirigir os actores, admiráveis (sobretudo os homens, uma vez que Beatriz Batarda acabou por ficar aprisionada num registo vocal agudo que lhe permitiu menos jogo do que o dos seus colegas - e no seu melhor momento, um monólogo veemente, largava esse registo). Marco Martins soube não só proteger a sensação de que as cenas se criavam cada noite pela 


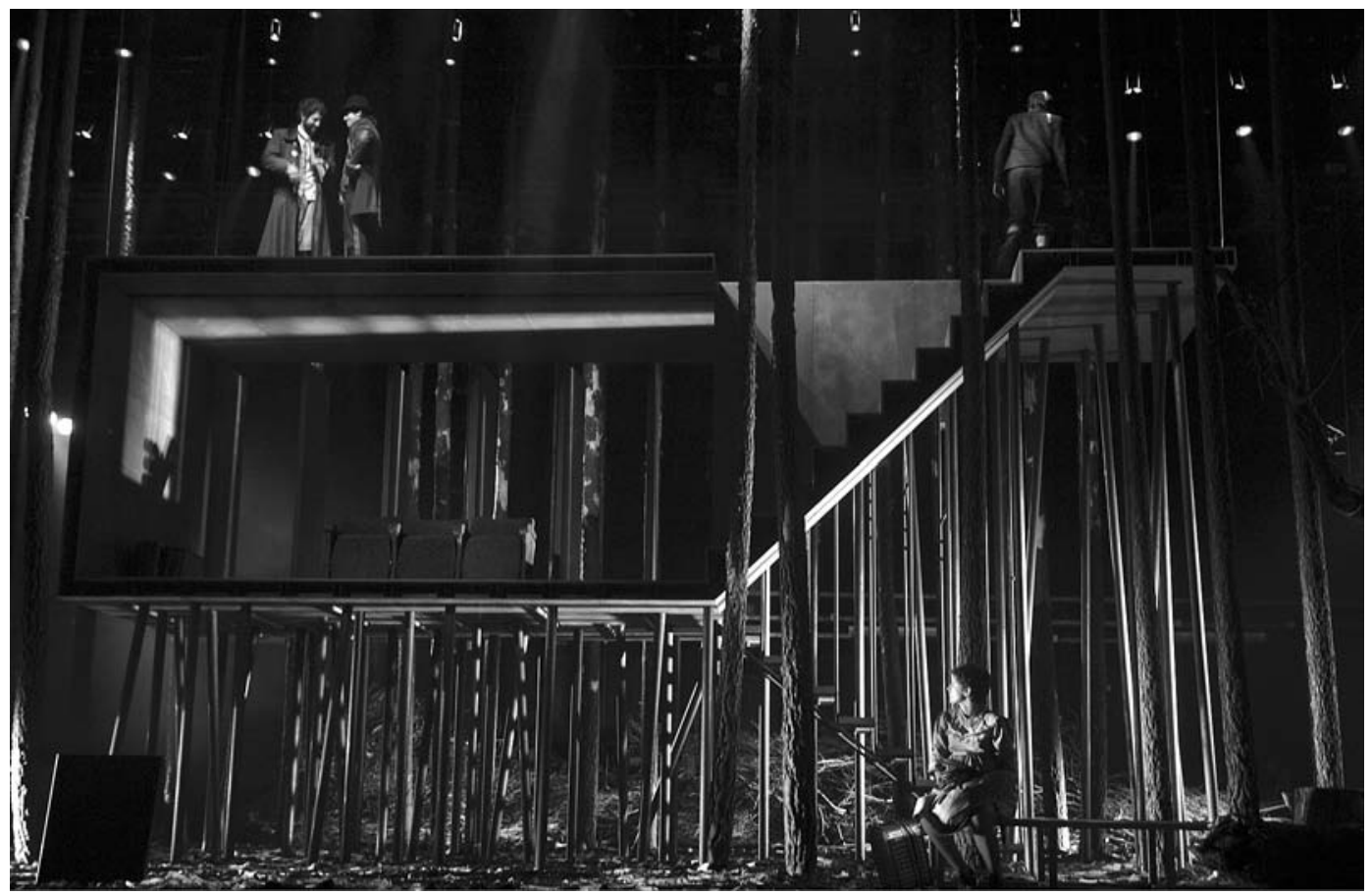

primeira vez mas também criar acontecimento com soluções de encenação, como virar de repente o discurso de uma cena directamente para a plateia, interpelando o público. Soube ainda, e souberam magnificamente os actores, jogar com os tempos das falas e dos movimentos.

Soube ainda coordenar uma equipa de criadores excepcionais. Outro dos protagonistas do espectáculo era, no bom sentido, a cenografia de João Mendes Ribeiro. Este arquitecto e cenógrafo, um pouco mais velho (nasceu em 1960), quis criar uma "paisagem mental" - e conseguiu. Tendo pela frente o desafio da alternância de cenas de exterior e interior, entre sanatório e floresta, ou mais precisamente, entre quarto, varanda, floresta, cemitério e estufa, não optou por fazer sair e entrar elementos, mas sim por fazer os actores circular entre os diferentes espaços: perdeu-se assim a possibilidade de introduzir surpresas cenográficas ao longo do espectáculo mas ganhou-se a surpresa de um espaço misterioso, assombroso e essencial, quase todo ocupado por troncos de pinheiro - e ganhouse a dinâmica das trajectórias das personagens por essa floresta, o que em muito serviu tanto a dramaturgia como o ritmo cénico. 0 cenógrafo também não optou por arrumar de um lado o interior e de outro qualquer lado o exterior: suspendeu o sanatório quase a meio do palco, no meio das árvores, como caixa feita de ferro oxidado, placas de madeira e cimento, assente em pilares que replicavam os troncos e faziam lembrar certos edificios de Le Corbusier. Esse dispositivo mais abstracto e construtivista (mas fisicamente rude nos materiais) visava, nas suas palavras, consubstanciar "a estranheza da paisagem ficcional e onírica onde decorre a acção". Segundo o cenógrafo (apud Guerreiro 2004: 19), "a utilização das formas simples, austeras e de rigor geométrico, a tendência para a redução do número de elementos e de operações envolvidas na composição e a vontade de conseguir o máximo de tensão com os mínimos meios formais são caracteristicas comuns a todos os meus cenários."

0 desenho de luz, de Nuno Meira, explorou admiravelmente essa cenografia, ajudando a definir cada espaço e a ir mudando as temperaturas da cenografia durante o longo espectáculo. Ao fundo, entre as árvores, surgia de vez em quando a orquestra: cinco instrumentistas e por vezes (mais à frente e em cima) um soprano cantando poemas de Goethe em alemão, de modo a permitir "uma leitura um pouco mais abstracta" e remeter para a Europa central, escreveu o compositor e director musical Pedro Moreira. Um luxo, esse recurso a orquestra ao vivo: tão eficaz nas suas intervenções, na criação de "paisagens psicológicas", e, pela própria surpresa do canto lírico, abrindo o espectáculo a um diálogo entre modernidade e epocalidade.

Mendes Ribeiro gosta também de explorar "as dissonâncias entre o cenário (intemporal) e os figurinos (datados), reflectindo a sobreposição de tempos diferentes, que localiza a acção e confere espessura à história" (ibidem). Foi o que aconteceu neste espectáculo, no diálogo com os figurinos de Adriana Molder, que, em conjunto com a certeira caracterização de Sano de Perpesac, soube criar figuras ao mesmo tempo concretas e abstractas, contrastantes e homogéneas, de início do século XX e intemporais (veja-se o figurino de Nuno Lopes, recriando 0 arquétipo do principezinho exuperiano).

Mas vale a pena sublinhar: não bastava a reunião de tantos talentos. 0 que de mais notável este espectáculo tinha era a transformação do talento em acontecimento, graças a uma metodologia criativa que importa reter e experimentar. Disse um dia Picasso que "a arte é uma mentira que nos ajuda a descobrir a verdade". Sobretudo quando não se julga detentora da verdade a priorie quando sabe a cada momento inventar o seu método.

\section{Referência bibliográfica}

GUERREIRO, Mónica (2004), "Essencialidade, austeridade, silêncio", Sinais de cena, n. 2 2, APCT/CET, Dezembro, pp.18-21. 